\title{
Animals e investigación en neuropatología veterinaria
}

\section{Dr. Martí Pumarola i Batlle ${ }^{1}$}

La reciente aprobación de una nueva ley que regula la experimentación animal, vuelve a poner sobre la mesa una serie de consideraciones sobre este tema, al mismo tiempo que despierta diversas sensibilidades tanto a favor como en contra de la utilización de animales en diferentes ámbitos.

Como veterinario y profesor de la Facultad de Veterinaria de la UAB, querría aportar mi punto de vista sobre la utilización de animales. En nuestra facultad, enseñamos a los estudiantes todo lo referente al afecto y respeto hacia los animales, tanto en cuanto a su salud como hacia su actividad productiva. También enseñamos sobre el sufrimiento y como evitar el dolor, así como a denunciar el maltrato y luchar por los derechos de los animales. Utilizamos los animales para la docencia práctica en todas sus variantes, desde la disección hasta la exploración, la cirugía y finalmente las necropsias. Todas nuestras prácticas han sido previamente evaluadas y han recibido la aprobación del Comité de Bioética de la UAB. Paralelamente, se está potenciando, siempre que ello sea posible, el uso de modelos informáticos o de tecnologías alternativas para disminuir esta utilización de animales.

Además de mis actividades docentes, llevo a cabo investigaciones en enfermedades nerviosas de los animales. Por ello necesito utilizarlos, pero haciéndolo únicamente de dos modos: en casos de enfermedad espontánea o utilizando animales de laboratorio.

\footnotetext{
${ }^{1}$ Dep. Medicina y Cirurgía Animales. Facultad de Veterinaria. Campus UAB
} 
Las enfermedades nerviosas animales son raras, y necesitan de neurólogos, veterinarios especialistas en este ámbito y de buenos medios. En nuestro campus disponemos de un Hospital Clínico Veterinario con un Servicio de Neurología y Neurocirugía excelente. Esto nos da la posibilidad de acceder a una cantidad y variedad muy importante de casos de animales con enfermedades nerviosas. Actualmente, algunas de estas enfermedades (neurodegenerativas, traumas, tumores, etc.) no tienen tratamiento y el destino de estos animales es la eutanasia humanitaria. Aquí podemos actuar los neuropatólogos, obteniendo el permiso del propietario del animal y la donación de su cadáver, aprovechando así para llevar a cabo el estudio postmortem de unos animales que si no serían incinerados o enterrados. Gracias a todo esto, una parte importante de nuestra investigación se fundamenta en la utilización de animales que presentan, de forma espontánea, enfermedades neurológicas, obteniendo así un material (células o tejidos) que pueden ser de gran interés para la investigación. Parte de este material tiene como destino el Banco de Tejidos Animales de Catalunya (BTAC, http://btac.uab.cat/), donde es almacenado en óptimas condiciones y está a disposición de aquellos grupos de investigación que puedan necesitar material similar.

Hay otra serie de enfermedades nerviosas, para cuyo estudio no disponemos de modelos animales espontáneos, o que en caso de existir, son muy costosos y precisan de la utilización de modelos animales de laboratorio. En nuestro caso, también llevamos a cabo parte de nuestra investigación estudiando las enfermedades producidas por priones en animales, haciendo uso de ratones a los que se inoculan los priones. En este caso, el control y supervisión del Comité de Bioética vuelve a ser fundamental. Las exigencias que se nos piden para utilizar animales de laboratorio son extremas y vienen reguladas por leyes como la que anteriormente comentábamos. Es necesario justificar, entre muchos parámetros el tipo y número de animales, las metodologías a utilizar, si habrá sufrimiento para el animal y su control, el personal 
cualificado que lo debe llevar a cabo y sobretodo que no haya alternativas a esta utilización de los animales. Una vez especificado adecuadamente, el comité resuelve y si resulta favorable, podemos proceder a la ejecución del proyecto. Una vez finalizado nuestro proyecto de investigación, enviamos las muestras de animales sobrantes al BTAC. Esto garantiza que si otro grupo de investigación quiere continuar nuestros estudios o llevar a cabo otros similares, podrá hacerlo sin recurrir a la utilización y sacrificio de nuevos animales, ya que únicamente solicitándolo al BTAC se los suministrarán de forma gratuita. De este modo, los bancos de tejidos aseguran una optimización máxima de las muestras que almacenan, asegurando de este modo una disminución de la utilización de animales para la investigación.

Finalmente, lo que para nosotros resulta más importante es que nuestra investigación no tiene como objetivo final únicamente el estudiar y paliar enfermedades nerviosas en animales. Estas enfermedades se presentan también en la especie humana. Por lo tanto, la mayor parte de nuestra investigación va directamente dirigida al estudio y solución, de ser el caso, de enfermedades nerviosas humanas. Los estudios de patología comparada que llevamos a cabo y los diferentes tipos de modelos animales que usamos, van destinados a este fin. 